\title{
Desafios para o ecoturismo no Parque Nacional da Serra da Bocaina: o caso da Vila de Trindade (Paraty, RJ)
}

\author{
Challenges for ecotourism in the National Park of Serra da \\ Bocaina: the case of the District of Trindade (Paraty, RJ, Brazil)
}

Bruna Ranção Conti, Marta de Azevedo Irving

\begin{abstract}
RESUMO
O município de Paraty (RJ) é reconhecido como um dos municípios de maior atratividade turística no Estado do Rio de Janeiro e compreende também $40 \%$ da área do Parque Nacional da Serra da Bocaina (PNSB), uma importante área protegida para a conservação do bioma Mata Atlântica. Nesse contexto, o ecoturismo emerge como alternativa potencial para a conservação da biodiversidade regional e também para a inclusão social, em ambientes ambientalmente e socialmente vulneráveis. Com base nesta afirmação, este artigo incide sobre a interpretação da vila de Trindade, situada no município de Paraty e parcialmente no interior do Parque Nacional da Serra da Bocaina, sobre o desenvolvimento turístico no local. A intenção neste caso é interpretar, pela perspectiva local, os efeitos do turismo sobre os modos de vida na localidade e sobre a conservação da biodiversidade no âmbito do PNSB. No plano metodológico, a pesquisa se baseou em revisão bibliográfica e documental, além de entrevistas em profundidade dirigidas, principalmente, às lideranças da população local de Trindade. A partir dos resultados obtidos é possível afirmar que, ao mesmo tempo em que o aumento progressivo no número de turistas é percebido como vantagem econômica pelos trindadeiros, o turismo é também entendido como ameaça à conservação da biodiversidade na região, em função do aumento da pressão antrópica sobre a base de recursos naturais. Da mesma forma, mudanças no cotidiano local são também identificadas como problemas a serem enfrentados. Diante disso, os trindadeiros não parecem ainda ter clareza sobre como compatibilizar o atendimento às necessidades dos turistas e a demanda por aumento de sua renda, com o compromisso de conservação da natureza e valorização de suas atividades tradicionais. Assim, o ecoturismo representa ainda não uma realidade, mas uma potencialidade a ser consolidada nesta localidade, no futuro.
\end{abstract}

PALAVRAS-CHAVE: Parque Nacional; Ecoturismo; Desenvolvimento. 


\section{ABSTRACT}

Paraty $(R J)$ is recognized as one of the biggest tourist attractiveness among the municipalities of the state of Rio de Janeiro and also comprises $40 \%$ of the Bocaina Mountains National Park (PNSB, in Portuguese) area, an important protected area for the conservation of the Atlantic Forest biome. In this context, ecotourism emerges as a potential alternative for the conservation of regional biodiversity and also for social inclusion in environmentally and socially vulnerable environments. Based on this claim, this article focuses on the interpretation of Trindade town, located in the municipality of Paraty and partially inside the Bocaina Mountains National Park, on the tourist development on the site. The intention is to interpret, through the local perspective, the effects of tourism on the ways of life in the locality and on the conservation of biodiversity within the park. Methodologically, the research was based on literature and document review and on interviews in depth mainly with leaders of the local population of Trindade. From the results obtained, it is clear that, while the progressive increase in the number of tourists is perceived as an economic advantage by the inhabitants, tourism is also perceived as a threat to biodiversity conservation in the region, due to the increased anthropic pressure on the natural resource base. Likewise, changes in the local daily life are also identified as problems to be addressed. Thus, the locals are still unclear about how to reconcile the addressing of the tourists needs and the demand for increasing their income, with a commitment to nature conservation and appreciation of their traditional activities. Thus, ecotourism is not yet a reality, but a potentiality to be consolidated at this location in the future.

KEYWORDS: National Park; Ecotourism; Development.

\section{Introdução}

O desenvolvimento turístico tem sido cada vez mais considerado como uma importante alternativa econômica em associação às áreas naturais protegidas (BODSTEIN, 1992). Isto ocorre, em especial, no caso dos parques nacionais, seja pela pressão da demanda que transforma os recursos naturais em sonhos de consumo contemporâneos, seja pelo entendimento, por parte do movimento ambientalista, de que o turismo representa um caminho possível para a compatibilização entre as distintas formas de uso e apropriação dos recursos naturais pelos grupos sociais envolvidos e a proteção da natureza nos territórios protegidos. No entanto, esses territórios, quando normatizados por uma legislação restritiva (como ocorre no caso dos parques nacionais), são frequentemente interpretados como causa de processos de exclusão social. Mas, ao contrário desta percepção, o desenvolvimento turístico poderia representar um caminho alternativo viável, em alguns casos, para a promoção do desenvolvimento, em consonância com o compromisso de proteção ambiental.

Por esta via, Luchiari (2000) aponta que, segundo uma nova ordem mundial de desenvolvimento em busca de sustentabilidade econômica, ambiental e social, o planejamento em turismo passa a depender da atribuição de novos papeis à população local, além de uma política de inclusão social, principalmente em áreas mais sensíveis à interferência humana. Sob esta perspectiva, para Coriolano (2005), a atividade turística 
pode ser capaz de provocar profundas transformações na forma de apropriação e uso do espaço pelos grupos sociais envolvidos, quando reorienta os usos desse espaço, como no caso de parques nacionais, com forte apelo turístico. Nesse caso, torna-se necessária a construção de uma nova proposta para o setor que considere as características endógenas como principal subsídio para a implementação de estratégias e ações planejadas (CORIOLANO, 2005), sendo esta, no caso dos parques, o ecoturismo uma opção para tal. Essa necessidade se torna ainda mais evidente a partir do momento em que o turismo passou a ser incorporado à agenda ambiental mundial, por meio do debate sobre o ecoturismo, tema fundamental no planejamento do uso público em parques nacionais.

Nesse sentido, este vem sendo reconhecido como uma das mais importantes alternativas às formas convencionais de desenvolvimento do turismo, principalmente quando associado às áreas naturais protegidas (APs). E, desde então, o turismo, nos moldes do então denominado "ecoturismo", vem sendo interpretado como alternativa potencial para a promoção do desenvolvimento local ${ }^{1}$ e a conservação da natureza em áreas protegidas, como no caso dos parques, prioridades com este objetivo no caso brasileiro (IRVING, 2008). E, sendo assim, o ecoturismo, se bem planejado, poderia gerar benefícios tanto à conservação da biodiversidade, como à proteção dos modos de vida local, potencializando a articulação entre desenvolvimento social e econômico local, e tendo a proteção da natureza como compromisso, conforme discutido por Deori e Das (2013).

Esse cenário potencial para o desenvolvimento do ecoturismo é ilustrado, com clareza, na vila de Trindade, uma vila de pescadores, no Distrito de Paraty-Mirim, no município de Paraty, parcialmente localizada no interior do Parque Nacional da Serra da Bocaina (PNSB). É importante mencionar, neste caso, que o município de Paraty é reconhecido como uma das áreas com maior atratividade turística na Costa Verde do Estado do Rio de Janeiro, e compreende $40 \%$ do PNSB, o que reafirma a sua importância no debate aqui proposto.

Diante do exposto, o objetivo do presente trabalho é interpretar a percepção local sobre o desenvolvimento do turismo na vila de Trindade, para que se possa avaliar em que medida a proposta de desenvolvimento turístico em curso atende aos pressupostos conceituais que orientam o debate sobre ecoturismo, no que diz respeito aos seus efeitos sobre os modos de vida locais e a conservação da biodiversidade no Parque Nacional da Serra da Bocaina. Nesse sentido, é importante mencionar que, segundo Goodey e Gold (1986), a percepção humana, as experiências pessoais e as características culturais dos indivíduos e coletividades locais constituem ponto de partida para o melhor entendimento do espaço ou ambiente em que vivem, sendo a análise dos fatores subjetivos e cognitivos a base para se pensar estratégias mais adequadas de desenvolvimento turístico, na tentativa de se alcançar a sustentabilidade da atividade (SILVEIRA, 2002) e, portanto, a minimização dos impactos sobre a base de recursos naturais (no caso dos parques nacionais), e a valorização das populações locais inseridas em seu interior ou entorno.

Nesse sentido, no plano metodológico, a pesquisa qualitativa se baseou em revisão bibliográfica e documental, além de uma pesquisa de 
campo envolvendo principalmente observação direta e a realização de entrevistas em profundidade dirigidas às representações e/ou lideranças da população de Trindade, referidas neste trabalho como "atores locais". Godoi e Balsini (2010) ressaltam ainda que a ênfase da pesquisa qualitativa é interpretar os significados e as intenções dos atores sociais investigados, de modo que os dados obtidos sejam representações dos atos e das expressões humanas, o que exige a imersão do pesquisador no contexto que será analisado. Desse modo, no caso de estudos qualitativos, o objetivo das entrevistas "em profundidade", como método de coleta de dados, é abordar a complexidade das relações, a partir do ponto de vista subjetivo dos atores sociais envolvidos em determinado contexto. A pesquisa qualitativa explora um tema a partir da busca de informações, percepções e experiências para que estas sejam analisadas de forma estruturada. Entre as principais vantagens dessa abordagem está a flexibilidade de permitir ao informante da pesquisa definir os termos das respostas, e ao entrevistador ajustar livremente as perguntas ao contexto abordado (FONTANA; FREY, 1994). Neste sentido, a entrevista foi utilizada na pesquisa para levantar dados essencialmente subjetivos, os quais se relacionam com os valores, as atitudes e as opiniões dos sujeitos entrevistados.

As entrevistas que compõem esta pesquisa foram realizadas em julho de 2010, envolvendo sete interlocutores locais, selecionados pela técnica de "bola de neve", segundo a qual, o primeiro entrevistado indica o seguinte e assim sucessivamente, considerado concluído o processo quando as respostas obtidas já não trazem novas indicações (BALDIN; MUNHOZ, 2011). É importante também explicar que apesar do número reduzido de entrevistas, os atores sociais selecionados são moradores atuantes e críticos com relação ao desenvolvimento do turismo na localidade, e tem vivenciado o processo turístico desde os seus primórdios, assim como vivem na localidade desde antes da instalação efetiva da equipe de gestão do parque, no ano de 2008. Assim, as entrevistas realizadas partiram de dois eixos principais de análise: 1) a visão local sobre a relação entre 0 turismo e os modos de vida, e 2) a visão local sobre a relação entre turismo e proteção da natureza no PNSB. Elas foram transcritas na íntegra e analisadas por meio de uma adaptação da Análise de Conteúdo, a partir de temas prioritários de análise. Complementando a estratégia metodológica, foi também entrevistado o responsável institucional pela gestão do PNSB, para que fosse possível um melhor entendimento acerca da relação existentes entre os trindadeiros e a equipe de gestão do parque.

Para a problematização do Estudo de Caso abordado, a seguir é discutido o referencial teórico de inspiração para a pesquisa realizada, centrado na discussão sobre os princípios fundamentais do ecoturismo e seus rebatimentos no caso de parques nacionais brasileiros, considerando também a importância da percepção dos "de dentro" (os moradores e "nativos") como elemento central para o desenvolvimento ecoturístico (MENDONÇA, 2004). O Estudo de Caso no qual se baseia este artigo é descrito na sequência do texto, e também está sistematizado em Conti et al. (2013), Conti (2011) e Conti, Irving e Corrêa (2011).

\section{Da noção de turismo à de ecoturismo: a busca pelos Parques Nacionais}


O turismo emerge como uma das mais importantes atividades econômicas mundiais a partir do final da década de 1970, sendo apontado por especialistas e órgãos oficiais como uma das atividades econômicas que mais crescem no mundo, adquirindo assim posição estratégica na economia de vários países. E como consequência desse cenário internacional, os países da América Latina passaram a investir, progressivamente, na promoção do turismo nos últimos anos, a partir da premissa que este poderia representar uma solução para todos os seus problemas. No entanto, o modelo de desenvolvimento turístico, adotado por grande parte desses países, vem sendo marcado pela lógica do mercado, priorizando o lucro e o rápido retorno dos investimentos. Nesse sentido, Turner e Ash (1991) discutem que o turismo, historicamente, além de se desenvolver a partir das desigualdades econômicas e das diferenças culturais entre os países (entre as regiões centrais e as periferias), tem representado fonte de acumulação de capital e riquezas, contribuindo ainda mais para o acirramento das desigualdades sociais, em escala global. Essa tendência faz com que este se torne também um veículo significativo de impactos negativos sobre os destinos nos quais se desenvolve, fortalecendo a lógica de continuidade de um processo prioritariamente baseado em estatísticas econômicas (CONTI, 2011).

Diante disso, o real potencial do turismo para a minimização de diversos problemas da sociedade contemporânea, como a pobreza crescente, as altas taxas de concentração de renda, os processos exclusivos e a degradação dos recursos naturais, como gostariam de afirmar alguns organismos internacionais, como a Organização Mundial do Turismo (MENDONÇA, 2004), passou a ser contestado por diversos pesquisadores e interlocutores dos movimentos sociais. Assim, para Sansbelló e Flores (2003), o turismo, desde o final da década de 1980, vem sendo caracterizado por um período de transformação, com a progressiva decadência do modelo tradicional (desenvolvido, preferencialmente, no litoral e desencadeador de uma série de problemas aos locais visitados), e o fortalecimento de "novos turismos" ou "turismos alternativos".

Mas este debate se insere em um contexto mais amplo sobre o modelo de desenvolvimento adotado pelos países industrializados e reproduzido pelas nações em desenvolvimento, pautado nos indicadores de crescimento econômico, incentivo crescente ao consumo e à superexploração dos recursos naturais. A crítica a esse modelo foi consolidada de forma marcante, a partir de 1987, com a difusão do Relatório Brundtland (elaborado pela Comissão Mundial sobre Meio Ambiente e Desenvolvimento). E, como alternativa a tal tendência, foi proposto o conceito de "desenvolvimento sustentável" como um contraponto de reflexão na busca de cenários futuros para o desenvolvimento. A formulação deste conceito (ou utopia) visou à conciliação entre desenvolvimento econômico, melhoria do bem-estar social e conservação da natureza, proposta que passou a ser incorporada em políticas públicas, por diversos segmentos, dentre eles o turismo. $\mathrm{E}$, sendo assim, ao longo da década de 1990, com a crescente valorização da natureza nos contextos nacional e internacional, e a procura cada vez maior por espaços naturais como 
destinos turísticos, o turismo em associação às áreas naturais protegidas passou a se expandir sob o viés do denominado "ecoturismo".

No plano global, Weight (1993) argumenta que o ecoturismo passou a ser então preconizado no final dos anos 1980 e início dos anos 1990, como uma alternativa econômica capaz de beneficiar tanto a manutenção dos espaços naturais protegidos, quanto as populações locais que dependem dos recursos naturais para a sua sobrevivência. Em âmbito internacional, o ecoturismo ganhou a cena política também na década de 1990, principalmente em função da realização da Conferência das Nações Unidas sobre o Meio Ambiente e o Desenvolvimento (Rio 92), no Rio de Janeiro. Desde então, o ecoturismo tem sido entendido como uma alternativa capaz de conciliar os compromissos de conservação da biodiversidade, a sensibilização da sociedade com relação às questões ambientais e a manutenção econômica das localidades afetadas pela criação de áreas protegidas, principalmente no caso de parques nacionais (RODRIGUES, 2009). Esta proposta de desenvolvimento ecoturístico viabilizaria ainda que os diferentes segmentos da sociedade fossem incluídos nos processos de planejamento, operação e monitoramento do setor, expressando suas ideias e receios, identificando seus interesses, suas necessidades e as formas com que esperam se beneficiar (NELSON; PEREIRA, 2004). E, idealmente, se poderia buscar até mesmo uma gestão comunitária do ecoturismo, o que tenderia a possibilitar ainda o contato do turista com o patrimônio e o modo de vida das populações locais. $O$ entendimento do ecoturismo se efetivaria, nesse sentido, como um subsistema interligado a outros sistemas (meio ambiente, educação, cultura), sendo o mesmo baseado em um arranjo socioprodutivo de base comunitária (SAMPAIO; ZECHNER; HENRÍQUEZ, 2008). Estes autores enfatizam ainda que as principais características do ecoturismo comunitário estão ligadas à criação e fortalecimento de canais de comunicação entre visitantes e visitados, havendo nesta interação, respeito mútuo entre turista e morador, e a vivência da dimensão espaço-tempo, regulada pelo ciclo natural de um modo de vida mais conectado com a natureza. Importante considerar também que, desde a década de 1990, em resposta aos compromissos assumidos pelo país, no âmbito da Convenção da Diversidade Biológica ${ }^{2}$ (CDB), uma ampliação considerável no número de áreas protegidas brasileiras vem ocorrendo e, entre elas, vários parques nacionais, categoria de manejo que, segundo Costa (2002), constitui a principal oferta para o ecoturismo no país.

Conquanto não pareça ainda haver um consenso sobre uma definição globalmente aceita para o ecoturismo, a base conceitual de maior alcance, atualmente, tanto em termos de produções científicas estrangeiras quanto nacionais, enfatizam o compromisso de proteção da natureza e a responsabilidade social para com os atores locais (WESTERN, 1999) como diretrizes norteadoras para tal. Além disso, o compromisso de participação social emerge como garantia ética de sustentabilidade em um processo efetivo de desenvolvimento do ecoturismo. Nesse sentido, Murta e Goodey (2002) ressaltam ainda que a população local deve ter noção do valor de seu patrimônio, tanto material quanto imaterial, e deve ser capaz de decidir 
sobre aquilo que deseja compartilhar e o que deseja manter para si, como sua identidade e memória.

No contexto de política pública nacional, a Embratur (1994) conceitua ecoturismo como "um segmento da atividade turística que utiliza, de forma sustentável, o patrimônio natural e cultural, incentiva sua conservação e busca a formação de uma consciência ambientalista através da interpretação do ambiente, promovendo o bem estar das populações envolvidas". Mas Grant (1995) enfatiza ainda que o ecoturismo envolve educação e interpretação do ambiente natural, que inclui a leitura sobre natureza e cultura de forma integrada.

Nesse sentido, Eagles (1995) define que o uso turístico de ambientes naturais deve estar associado a alguns compromissos inerentes a essa prática, como a proteção ambiental contínua, a participação social assegurada no processo, o desenvolvimento das populações locais e a reversão de parte dos benefícios econômicos gerados para as localidades envolvidas. $\mathrm{O}$ autor afirma ainda que parece existir um consenso emergente de que alguns nichos de mercado, como o ecoturismo, o turismo de aventura e o turismo silvestre, tendem a potencializar o desenvolvimento do turismo em áreas naturais protegidas, de forma sustentável. E, Segundo Deori e Das (2013), o ecoturismo é considerado, atualmente, como o "segmento" que mais tem crescido no mundo, e de forma acelerada, dentre todos os que compõem o mercado turístico.

Para que se possa contextualizar as tendências de expansão do ecoturismo no plano global, vale contextualizar que, de acordo com dados da OMT $(2013)^{3}$, a previsão de crescimento do turismo para o ano de 2013 foi de $7,5 \%$, enquanto que no mesmo período a expectativa para 0 crescimento do ecoturismo foi de cerca de $20 \%$, o que vem a reafirmar a importância deste segmento em planejamento turístico, principalmente em relação às áreas protegidas e à valorização das populações que vivem em seu interior ou entorno, uma vez que essas áreas são de grande apelo para os ecoturistas que buscam a natureza preservada em suas escolhas. Além disso, de acordo com pesquisa encomendada pelo Ministério do Turismo em $2011^{4}$, cerca de $30 \%$ dos turistas estrangeiros que viajam ao Brasil buscam o ecoturismo e o turismo de aventura como opções, o que reforça a importância de planejamento do turismo em associação às estratégias de proteção da natureza, principalmente quando desenvolvido em AP e, em especial, nos parques nacionais. Sendo assim, compatibilizar os efeitos de conservação da biodiversidade com o planejamento e a gestão do turismo, representa, atualmente, um dos maiores desafios para o Brasil, principalmente quando se considera, por meio dos dados globais sobre biodiversidade, que o Brasil é um dos 12 países mais megadiversos em escala global, abrigando de 15 a $20 \%$ das espécies vivas do planeta (IRVING, 2008).

No entanto, Sansolo (2006) argumenta que, embora o Brasil possua a maior biodiversidade do planeta (e assim, em tese, represente um país de grande atratividade para o ecoturismo nacional e internacional), ainda não dispõe das condições necessárias para garantir o equilíbrio entre o processo de conservação da biodiversidade e o desenvolvimento do turismo em áreas naturais protegidas, uma vez que a natureza é ainda interpretada 
como "mercadoria". Neiman, Mendonça e Schlindwein (2008) alertam ainda para o perigo da lógica do ecoturismo em sacralizar a natureza para torná-la mais "vendável", o que poderia intensificar os processos de degradação ambiental e os riscos de descaracterização da cultura local.

Outra questão que emerge também do debate sobre o crescimento do ecoturismo em parques nacionais é como garantir que os recursos derivados da visitação sejam aplicados em conservação da natureza e em benefício das populações locais. Irving (2008) afirma que estudos realizados em áreas naturais brasileiras, de forte apelo ecoturístico, ilustram a tendência geral de exclusão das populações locais, com relação aos benefícios gerados no processo. Sendo assim, embora o retorno econômico do ecoturismo possa ser elevado, nem sempre é bem distribuído. Além disso, os interesses econômicos associados ao ecoturismo tendem a estimular o sobreuso de áreas naturais protegidas, o que constitui um sério risco ao seu equilíbrio natural, não só nas áreas prioritárias para desenvolvimento turístico, mas também em toda a sua área de influência.

Sob a ótica de planejamento, a autora destaca também dois obstáculos para o desenvolvimento do ecoturismo no Brasil: a limitação de recursos humanos qualificados e a limitada infraestrutura disponível nas áreas protegidas (APs) abertas à visitação. Nesse sentido, Conti e Irving (2010) identificam, também como dificuldade para o processo, o fato de os órgãos governamentais dificilmente atuarem, em conjunto, no local de inserção de uma AP, o que gera conflitos entre prioridades de políticas públicas e uma atuação institucional distante da realidade local, o que é agravado por não existir ainda um mecanismo sistemático de integração entre os órgãos federais, estaduais e municipais com atribuição na gestão de espaços protegidos. Esta desarticulação tende a resultar em ações segmentadas e pouco efetivas com relação à conservação de áreas de elevada biodiversidade, ou ainda, no aumento dos riscos com relação à integridade dessas áreas. Todos esses problemas podem ser observados, de maneira recorrente, no processo de planejamento e gestão das APs no Estado do Rio de Janeiro.

Considerando a sua importância econômica e ambiental, além dos desafios que precisará enfrentar, nos próximos anos, como sede de importantes eventos de alcance global (a Copa do Mundo, em 2014, e os Jogos Olímpicos, em 2016), o planejamento do ecoturismo nas APs do Rio de Janeiro vem ganhando destaque na agenda de políticas públicas do Estado. Esse contexto gera tensões para a gestão da biodiversidade e demanda esforços governamentais sistemáticos para a compatibilização entre as políticas públicas de desenvolvimento e de proteção da natureza, principalmente no caso dos parques (IRVING; MATOS, 2006), categoria de manejo de proteção integral prioritária para 0 desenvolvimento do ecoturismo.

No contexto específico do Parque Nacional da Serra da Bocaina, foco desta pesquisa, não se pode negligenciar que mais da metade da sua extensão está localizada na região da Costa Verde do Estado do Rio de Janeiro (Itaguaí, Mangaratiba, Rio Claro, Angra dos Reis e Paraty, sendo que os dois últimos municípios abrigam $61,9 \%$ da área do parque - $21,6 \%$ e $40,3 \%$, respectivamente), uma das regiões turísticas mais procuradas do 
Estado. Importante ressaltar também que os municípios de Angra dos Reis e Paraty têm sua atividade econômica intimamente ligada ao comércio e à prestação de serviços, derivados principalmente do turismo, o que representa mais da metade do PIB desses municípios (IBAMA, 2002). Ou seja, a área de inserção do PNSB abriga um dos principais remanescentes de floresta atlântica ainda em bom estado de conservação e, ao mesmo tempo, constitui um destino turístico associado a forte e crescente demanda pelo mercado, com destaque para a vila de Trindade, no município de Paraty (CONTI, 2011).

Diante dos desafios anunciados para a consolidação do ecoturismo nos parques nacionais e, especificamente, no contexto socioeconômico da área de inserção do PNSB, área protegida focal nesta análise, a percepção dos "de dentro" (no caso os moradores da área de inserção do PNSB, e mais especificamente os moradores da vila de Trindade, recorte desta pesquisa) é de fundamental importância para a compreensão das limitações ainda recorrentes para o desenvolvimento do ecoturismo no local, e os caminhos visualizados pelos trindadeiros como possíveis alternativas futuras com este objetivo.

\section{Estudo de Caso: o Parque Nacional da Serra da Bocaina e a vila de Trindade}

O Parque Nacional da Serra da Bocaina (PNSB) foi criado em 1971 (Decreto n. $^{\circ} 68.172$ de 04 de fevereiro de 1971) e compreende, atualmente, uma área de 104 mil ha. O Parque tem sua sede no município de São José do Barreiro, embora o seu território se estenda por diferentes municípios entre os estados de São Paulo e Rio de Janeiro. O PNSB representa um dos principais remanescentes de floresta atlântica ainda em bom estado de conservação, e está localizado na divisa entre os estados de São Paulo e Rio de Janeiro, inserido em importantes municípios turísticos desses estados, como Angra dos Reis, Paraty (RJ) e Ubatuba (SP) (Figura 1), todos também sob forte pressão da expansão urbana e do turismo (CONTI, et al, 2013):

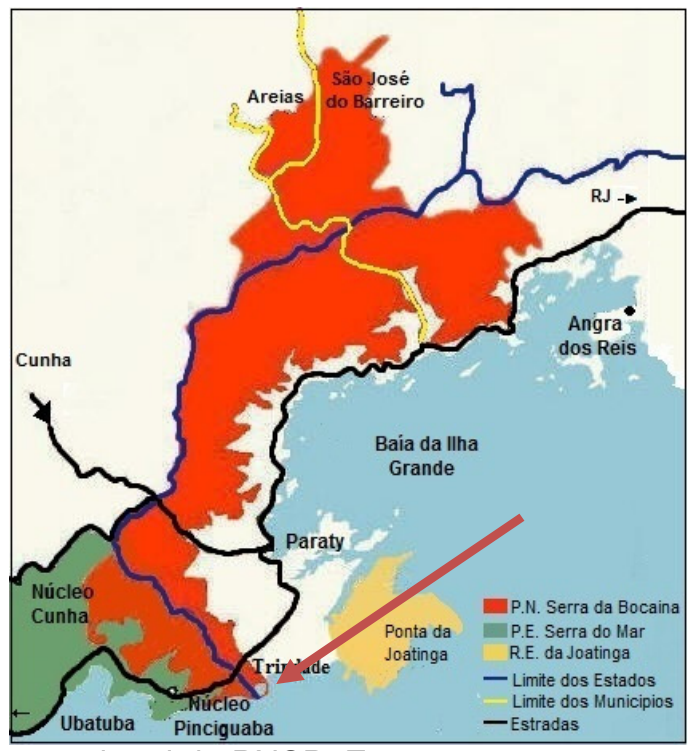

Figura 1: Inserção regional do PNSB. Fonte: www.paraty.com.br (adaptado).

Figure 1: Regional Integration of PNSB. Source: www.paraty.com.br (adapted). 
A vila de Trindade, foco prioritário desta pesquisa, por sua vez, está localizada parcialmente nos limites do PNSB e tem se destacado como um dos principais destinos indutores do turismo na área de inserção desta unidade de conservação. Além disso, em função da beleza cênica dos vários pontos turísticos do parque, várias trilhas e caminhos em seu interior têm sido explorados pelo turismo regional, com destaque para a vila de Trindade, o que vem desencadeando inúmeros impactos sobre a base de recursos naturais e sobre o modo de vida local.

A história da vila de Trindade se associa à luta dos seus habitantes para permanecerem no local. Essa luta começou em 1970, quando a multinacional Brascan tentou construir na vila um condomínio de luxo, passando a comprar, para tal, terras dos nativos. Como muitos se recusaram a deixar as suas casas, a empresa enviou para a área jagunços armados, reclamando o direito de posse da terra, destruindo as raras construções existentes e desabrigando os moradores (PEREIRA, 2001). Entretanto, após uma conturbada disputa judicial, a população de Trindade conseguiu garantir o direito à terra, com o apoio de alguns turistas que frequentavam a vila, e que passaram a assessorá-la e apoiá-la nesse movimento. Esses turistas foram os responsáveis pelo fortalecimento da difusão do caso nas mídias nacional e internacional, trazendo ao debate público a invasão da área, o que despertou o interesse de um importante jurista (Dr. Sobral Pinto) pela causa, que através de disputas judiciais garantiu o direito dos moradores de permanecerem no local.

Não obstante, nas décadas de 1970 e 1980, o turismo era ainda incipiente na vila, sendo constituído, principalmente, por visitantes mais identificados com a característica preservada da região, principalmente os hippies ou perfis associados. Mas, após a construção da rodovia PRT-101 (popularmente conhecida como Morro do Deus-me-livre), único acesso regular à vila de Trindade, esse cenário começou a se transformar. Em 1999, a pavimentação dessa estrada e a chegada da telefonia à vila contribuíram também para o aumento considerável do fluxo de visitantes ao local, o que ocasionou a atração de empreendedores de diversas localidades, que passaram a investir em equipamentos turísticos na vila. Assim, como enfatiza Pereira (2001), casas de veraneio, pousadas, restaurantes e bares foram construídos de modo desorganizado, e concorreram com as práticas comerciais dos nativos, aumentando o impacto de desordem social já bastante grave com a chegada ao local de novos residentes, o que vem agravando, ainda mais, o processo de exclusão social. Nesse percurso, Oliveira (2005) afirma que grande parte da população da vila de Trindade, assim como de diversas áreas do município de Paraty, vem sofrendo, desde então, um processo de marginalização resultante do "desenvolvimento" proporcionado pelo turismo, em bases insustentáveis.

Esse problema se agravou, em parte, devido à ausência, por cerca de 40 anos, de uma equipe de gestão do PNSB na área de Trindade. E foi somente em 2008 que a administração do parque passou a desenvolver iniciativas de gestão dirigidas a minimizar os impactos do desenvolvimento desordenado do turismo na área e a buscar a consolidação efetiva da AP, o que vem gerando uma situação de tensão entre a equipe da gestão pública 
e a população local, tendo em vista as ações previstas de ordenamento do turismo. O fato do turismo ser a principal atividade econômica e fonte de renda dos moradores da vila, tende a agravar ainda mais esta situação, já que as ações propostas de ordenamento são localmente percebidas como prejudiciais à manutenção/ampliação das atividades já desenvolvidas no cotidiano desse grupo social (OLIVEIRA, 2005).

Tendo em vista o contexto descrito e para elucidar o processo histórico de desenvolvimento do turismo na vila de Trindade, uma análise ainda que preliminar dos impactos do turismo sobre o modo de vida local, e sobre as tensões entre desenvolvimento do turismo e proteção da natureza na região, parece essencial para que se possa refletir sobre tendências futuras. Assim, com base no referencial teórico apresentado e na leitura dos trindadeiros, pretende-se avaliar em que medida o desenvolvimento do turismo na vila de Trindade vem sendo planejado e implementado de acordo com os princípios norteadores do ecoturismo.

\section{A relação entre turismo, modos de vida local e proteção da natureza pela perspectiva dos trindadeiros}

Para avaliar a percepção local sobre o turismo e sua relação com o PNSB, como anteriormente mencionado, foram entrevistados sete trindadeiros, selecionados pela técnica "bola de neve", cujo perfil está sistematizado no Quadro 1, a seguir:

Quadro 1: O perfil dos atores locais entrevistados

\begin{tabular}{|c|c|c|c|}
\hline $\begin{array}{c}\text { Sujeitos } \\
\text { da pesquisa }\end{array}$ & Perfil dos Entrevistados & $\begin{array}{c}\text { Sujeitos da } \\
\text { pesquisa }\end{array}$ & Perfil dos Entrevistados \\
\hline 1. SA & $\begin{array}{l}\text { Sexo: Masculino } \\
\text { Faixa etária: superior a } 80 \\
\text { anos } \\
\text { Escolaridade: Analfabeto } \\
\text { Profissão: Trabalhador } \\
\text { Rural. } \\
\end{array}$ & 5. SE & $\begin{array}{l}\text { Sexo: Masculino } \\
\text { Faixa etária: } 21 \text { a } 30 \text { anos } \\
\text { Escolaridade: Superior } \\
\text { Completo (Jornalismo) } \\
\text { Profissão: Pousadeiro }\end{array}$ \\
\hline 2. SB & $\begin{array}{l}\text { Sexo: Feminino } \\
\text { Faixa etária: superior a } 80 \\
\text { anos } \\
\text { Escolaridade: Analfabeta } \\
\text { Profissão: Dona de Casa }\end{array}$ & 6. SF & $\begin{array}{l}\text { Sexo: Masculino. } \\
\text { Faixa etária: } 21 \text { a } 30 \text { anos } \\
\text { Escolaridade: Superior } \\
\text { Completo (Administração) } \\
\text { Profissão: Pousadeiro }\end{array}$ \\
\hline 3. SC & $\begin{array}{l}\text { Sexo: Masculino } \\
\text { Faixa etária: } 41 \text { a } 50 \text { anos } \\
\text { Escolaridade: } 2^{\circ} \text { Grau } \\
\text { Completo } \\
\text { Profissão: comerciante e } \\
\text { barqueiro } \\
\end{array}$ & 7. SG & $\begin{array}{l}\text { Sexo: Feminino } \\
\text { Faixa etária: } 51 \text { a } 60 \text { anos } \\
\text { Escolaridade: Superior } \\
\text { Incompleto (História) } \\
\text { Profissão: Educadora } \\
\text { Ambiental } \\
\end{array}$ \\
\hline 4. SD & $\begin{array}{l}\text { Sexo: Masculino } \\
\text { Faixa etária: } 21 \text { a } 30 \text { anos } \\
\text { Escolaridade: } 2^{\circ} \text { Grau } \\
\text { Completo } \\
\text { Profissão: pescador e } \\
\text { barqueiro } \\
\end{array}$ & & \\
\hline
\end{tabular}


Além destes, foi também entrevistado o atual gestor do PNSB, com a finalidade de buscar um melhor entendimento acerca da relação existentes entre os trindadeiros e a equipe de gestão do parque.

No entanto, antes de apresentar os resultados da análise em questão, é necessário retratar, brevemente, os acontecimentos recentes por que passou o município de Paraty, uma vez que as transformações econômicas do lugar têm rebatimento direto na história da vila de Trindade e, portanto, na percepção dos moradores sobre a relação entre turismo, modos de vida local e proteção da natureza, posteriormente retratada a partir de seus próprios relatos sobre as transformações que vivenciaram durante o processo.

Nesse sentido, é importante mencionar que, a partir da segunda metade do século XIX, a cidade de Paraty passou por períodos de forte declínio populacional e relativo isolamento, em decorrência da diminuição do uso do porto (cuja principal função era o escoamento do café produzido no Vale do Paraíba). E, após longo período de estagnação econômica na região, o turismo passou a ser impulsionado como principal alternativa econômica para o desenvolvimento regional, sobretudo, a partir do início da década de 1970, com a abertura da rodovia Rio-Santos, estrada que tinha entre seus objetivos a promoção do turismo no litoral norte de São Paulo e na região da Costa Verde do estado do Rio de Janeiro. Foi também neste momento que ocorreu a criação do Parque Nacional da Serra da Bocaina (em 1971), que, no entanto, permaneceria por cerca de 40 anos como um "parque de papel" (CONTI, 2011).

Posteriormente, com o asfaltamento da estrada do Morro do Deusme-livre, que liga Paraty à Trindade, segundo os moradores da vila, o desenvolvimento do turismo nessa localidade sofreu grandes transformações em curto espaço de tempo, o que resultou no aumento da pressão antrópica sobre a base de recursos naturais, no interior do PNSB.

$\mathrm{E}$, no processo, à medida que o turismo se desenvolvia, "a intenção das pessoas que trabalham com pesca e com roça foi mudando pro turismo" (SD). Ainda segundo a perspectiva local, este processo de aumento dos turistas na localidade desencadeou também "uma maior preocupação com a infraestrutura turística do local". A partir de então, "as pousadas foram melhorando e o turismo como um todo está bem melhor" (SD). No entanto, a limitada infraestrutura básica e turística para os meses de alta temporada (quando a vila chega a receber cerca de 40 mil pessoas em um final de semana) é interpretada, localmente, como desfavorável ao desenvolvimento do turismo, uma vez que tende a contribuir para o aumento da pressão sobre os recursos naturais.

O fato é que desde o início das transformações ocorridas na vila, os habitantes de Trindade percebem também uma forte transformação no perfil do turista que busca a localidade como destino. Para os trindadeiros, se antes eram os hippies que frequentavam a vila, após algumas melhorias na infraestrutura local (principalmente o asfaltamento da via de acesso à vila e a construção de algumas pousadas e restaurantes), o perfil da maior parte dos turistas que ali chega passou a ser representado por paulistas de classe média, em busca de sol, praia e contato com a natureza. Os trindadeiros 
afirmam também que, até que a denominada estrada do Morro do Deus-melivre fosse asfaltada, a localidade recebia turistas somente na época do verão, e esse fluxo não era suficiente para que a maioria dos nativos pudesse viver exclusivamente do turismo, como ocorre atualmente. Diante deste contexto, eles afirmam que o aumento no número de turistas trouxe tanto benefícios quanto prejuízos para a localidade. Porém, parece evidente a atual dependência da população local dessa fonte de renda. E mesmo quando os moradores da vila se classificam como pescadores ou roceiros, afirmam também trabalhar para o turismo nos meses de alta temporada. Tal interpretação pode ser evidenciada em alguns dos depoimentos obtidos pela pesquisa, como exemplificado a seguir:

Nós dependemos desse turista que vem pra cá, é a hora que a gente tem que trabalhar, nós da Trindade sabemos que a nossa dependência é do turismo, quando não tem turismo a gente vive até um baixo astral, a gente fica mal. Se tem turismo alivia tudo, por que nós dependemos dele (SC).

Dentre as transformações de seus modos de vida, como resultado do desenvolvimento turístico, são exemplificadas, por alguns, a adaptação de seus barcos de pesca em barcos de passeio ou, simplesmente, a cessão de seus quintais para camping, o que representa um primeiro movimento de transformação do modo de vida caiçara dos trindadeiros, como adaptação às necessidades dos turistas que visitam a área. Sendo assim, apesar do turismo ser entendido como um fator positivo para o desenvolvimento da vila (no que diz respeito ao aumento da renda), é também interpretado, pelos moradores, como um fator impactante e desestruturador da ordem social local.

Em relação aos problemas relacionados ao aumento do fluxo do turismo na região, esses atores sociais apontam a superlotação da vila em períodos de alta temporada (como natal, réveillon, carnaval e semana santa); o aumento do lixo e do esgoto; a contaminação e a degradação das áreas florestais, cachoeiras e praias; a violência; o excesso de ruídos; as drogas; e o trânsito, como as questões mais graves a serem enfrentadas. Esses problemas impactam tanto a natureza quanto o modo de vida local, gerando tensões e dificuldades para a gestão da área.

Além das consequências da superlotação nos períodos de alta temporada, mudanças indesejadas no dia-a-dia da população são também assinaladas como problemas resultantes do atual modelo de desenvolvimento do turismo na vila, principalmente porque afetam a cultura e o modo de vida local. Tais mudanças estão associadas, na visão dos trindadeiros, à descaracterização das festas populares, à transformação de hábitos alimentares e à renúncia progressiva das atividades de roça e pesca como meios de subsistência. É importante ressaltar ainda que a falta de tempo para a prática de tais atividades tradicionais, em função do trabalho e do esforço investido no turismo, costuma ser entendida como um problema à dinâmica local e restrição das possibilidades do "viver em comunidade", o 
que acaba por enfraquecer os laços sociais $e \quad o$ sentimento de pertencimento dos moradores ao local.

Mas apesar dos trindadeiros entenderem que vem ocorrendo a descaracterização da cultura local após o crescimento desordenado do turismo, é unânime a percepção de que "ainda existe na Trindade traços da cultura caiçara e modos de vida caiçara" (SD). Além da localização geográfica da vila no litoral, as atividades tradicionalmente ainda desenvolvidas, com destaque para a pesca artesanal, a roça, a fabricação de farinha e o artesanato, são também apontados como elementos que caracterizam tal grupo como caiçara.

É possível afirmar ainda que os anseios dos moradores locais com relação ao turismo dizem respeito a um maior ordenamento do setor e à compatibilização entre a melhoria de infraestrutura e a manutenção de suas atividades tradicionais. Nesse sentido, parte da população local tem se mobilizado para buscar meios de compatibilização entre os interesses de proteção da natureza e a manutenção do seu modo de vida e das atividades econômicas tradicionais. Essa mobilização vem ocorrendo a partir do fortalecimento da Associação de Moradores (AMOT), desde 2008, e com a sua articulação com a prefeitura de Paraty e com a equipe de gestão do PNSB.

Diante do exposto, alguns trindadeiros defendem a proposta de uma nova estruturação do turismo na Trindade, fundamentada nos seguintes pressupostos: a) planejamento e desenvolvimento do turismo a partir de um estudo de capacidade de suporte e da limitação do número de turistas na vila, b) ações de organização e fortalecimento contínuo da Associação dos Moradores da Trindade (AMOT) e, c) a instalação de um pedágio de acesso à vila. Essas três ações serão detalhadas a seguir, para que se possa compreender as propostas locais e também as controvérsias entre os próprios moradores de Trindade com relação a essas ações para 0 desenvolvimento turístico.

Em primeiro lugar, o estudo de capacidade de suporte buscaria estabelecer o número máximo de visitantes com relação à área protegida, levando-se em consideração as suas condições físicas, biológicas e de manejo. No caso da Trindade, este estudo teria por objetivo limitar o número de visitantes, tanto no PNSB (praias e trilhas) como em seu entorno (a vila). É importante ressaltar que essa ação foi proposta, originalmente, pelos administradores do PNSB, o que fez com que os moradores de Trindade se mobilizassem para garantir a representação dos seus interesses no processo. No entanto, a realização deste estudo representa um tema ainda em debate entre os próprios moradores da vila, uma vez que ainda não há uma visão consensual acerca das consequências de um estudo de capacidade de suporte.

Para os moradores de Trindade que acreditam no estudo de capacidade de suporte como uma importante ação para o planejamento do turismo na localidade, este poderia induzir a atração de perfis de turistas mais sensibilizados à importância da proteção ambiental e cultural da área, durante todo o ano. De acordo com esta perspectiva, seriam atraídos para o local, em tese, turistas com um poder aquisitivo mais elevado, em busca de 
melhor infraestrutura e lugares mais bem preparados para recebê-los. E, sendo assim, estes "poderiam gerar mais benefícios econômicos para a população e menos impactos negativos sobre os recursos naturais e sobre a cultura" (SE). Assim, para esse grupo de moradores da vila, o estudo de capacidade de suporte proporcionaria um melhor ordenamento do turismo, este estruturado não segundo a premissa de "quantidade", mas de "qualidade". Além de uma mudança no perfil do turista, os trindadeiros esperam ainda, com esse estudo, uma diminuição no impacto ocasionado pela sazonalidade, e acreditam, assim, que haverá a possibilidade de aumento da renda gerada pelo turismo. Esse é também o pensamento dos administradores do PNSB que tentam implementar esta ação e diversas outras, que possibilitariam a consolidação efetiva do parque na área da Trindade.

No entanto, alguns interlocutores da população local se mostram contrários à realização de um estudo de capacidade de suporte na Trindade, mesmo admitindo que a superlotação (em determinados períodos do ano) e a sazonalidade, trazem muitos prejuízos para a localidade. Esses são representados por cidadãos mais idosos e/ou que viveram mais diretamente o conflito de interesses pela posse das terras em Trindade. Para estes, a finalidade de um estudo como esse não seria simplesmente ordenar o turismo na Trindade, mas sim dificultar ainda mais a vida do trindadeiro, já que levaria à diminuição do número de turistas e, consequentemente, comprometeria a principal fonte de renda local. Além disso, esse grupo não acredita que um perfil de turista mais "qualificado" irá se interessar pelo destino Trindade, já que a localidade não possui infraestrutura básica e turística adequada para receber turistas mais exigentes. Assim, eles acreditam que com o estudo "os menores estabelecimentos seriam prejudicados, pois sem um grande número de turistas, eles ficariam sempre vazios" (SC).

Sendo assim, a possibilidade de um estudo de capacidade de suporte representa um ponto de divergência entre as lideranças envolvidas e, evidentemente, expressa parte das tensões locais. Da mesma forma, esse estudo expressa um conflito potencial entre parte da população de Trindade e a administração do PNSB, uma vez que um dos objetivos principais da atual equipe de administração do parque é o ordenamento do turismo na região, por meio de um estudo com este objetivo.

Além do estudo de capacidade de suporte, a consolidação do processo de organização da própria população e o fortalecimento da Associação de Moradores são também ressaltados na pesquisa como ações fundamentais para o planejamento e o desenvolvimento do turismo (segundo as premissas conceitos que orientam o ecoturismo), no local. É interessante destacar que os trindadeiros associam o parque com o resgate e fortalecimento da AMOT, o que é interpretado, por alguns, como um ponto positivo desse processo recente de esforços para a consolidação do PNSB. Com a necessidade de maior articulação entre a população local e a administração do parque, para que sejam debatidos os caminhos para o desenvolvimento na vila, a Associação (que antes estava enfraquecida) voltou a ter força e representatividade nas decisões locais. $E$, a partir de então, a população de Trindade passou a acreditar no seu poder de 
organização, tendo em vista que alguns de seus membros já reafirmam a necessidade de se buscar uma forma de desenvolvimento turístico baseada na gestão comunitária e no planejamento participativo.

Nesse sentido, os atores locais são a favor da instalação de um pedágio de acesso à vila, planejado e gerido por eles próprios. O objetivo do pedágio seria angariar recursos para a manutenção de serviços básicos que não estão sendo oferecidos pela prefeitura de Paraty e que são essenciais para o turismo, como por exemplo, a limpeza e manutenção das ruas e da estrada. Assim, os trindadeiros tendem a considerar a possibilidade de um pedágio, por eles controlado, como sinal de sua "independência", e como meio de remuneração das atividades que eles já vêm desenvolvendo na vila para atender aos turistas (como, por exemplo, a manutenção da estrada do Morro do Deus-me-livre e a limpeza das trilhas e cachoeiras). Esta proposta surge como uma alternativa à cobrança de ingresso para o visitante ter acesso ao PNSB - ação que a equipe de administração da área protegida pretende implementar após o parque ser dotado de uma infraestrutura turística mínima para a recepção de visitantes (como um centro de visitantes, lavatórios e toiletes, e lanchonete). No entanto, os moradores da vila acreditam que os recursos arrecadados com a cobrança de ingresso pela administração do parque não irão trazer qualquer benefício direto para a vila, mas somente para os turistas, já que estes recursos seriam geridos pelas instâncias públicas e não seriam revertidos para as necessidades dos moradores da vila. Sendo assim, o pedágio seria uma forma de controlar o acesso dos visitantes e, ao mesmo tempo, assegurar que os recursos advindos dos turistas sejam aplicados, diretamente, na própria localidade.

Mas para além dos conflitos potenciais decorrentes de um estudo de capacidade de suporte e da implementação da cobrança de ingresso para acesso à área do parque, outras ações da administração do PNSB vêm desencadeando também uma série de conflitos com a população local, como a recente retirada dos quiosques da Praia do Meio (única praia localizada no interior da área do PNSB, na Trindade, que conta com diversos quiosques nela instalados) e a realização, desde 2008, da denominada "Operação Verão" (operação de fiscalização realizada pela administração do parque em períodos de alta temporada, principalmente nos feriados do Carnaval e da Semana Santa, com o objetivo de sensibilizar os turistas para as causas ambientais e fiscalizar o uso dos recursos naturais e a limpeza nos atrativos naturais).

No que diz respeito à retirada dos quiosques, decisões judiciais vem ordenando, desde 2011, a demolição de bares instalados, de maneira irregular, na Praia do Meio, significativo atrativo turístico local. E todos os entrevistados na pesquisa realizada concordam que essa ação elimina a possibilidade de trabalho de diversos moradores. Sendo assim, acreditam que a administração do parque deveria oferecer condições para que os mesmos não perdessem esta fonte de renda. Sobre essa questão, o gestor do PNSB afirma não poder colaborar para o equacionamento do problema, já que os bares demolidos estavam ilegalmente instalados no local e, portanto, deveriam ser dali retirados para atender às exigências desta área de proteção integral. 
Com relação à Operação Verão, esta é uma medida de fiscalização conduzida pela administração do PNSB para que sejam minimizados os impactos ambientais causados por um grande número de turistas no interior da área do parque. No entanto, os trindadeiros alegam que não bastam inserções pontuais da administração do parque na área da Trindade, já que nos períodos em que as operações não acontecem, é a própria população que realiza as atividades de fiscalização e limpeza das trilhas e praias, o que reafirma o seu papel como protagonista para a conservação da biodiversidade na área. Os trindadeiros manifestam ainda o desejo que essas operações possam acontecer em parceria com eles próprios, para que possam gerar reais benefícios tanto para a vila quanto para a área do PNSB. Por fim, eles entendem que os resultados dessas operações não são divulgados para os moradores, o que, na percepção local, evidencia o distanciamento da administração, o que gera, consequentemente, a potencialização das tensões existentes.

Essa interpretação reafirma o interesse dos moradores em participar, de forma mais próxima à equipe do parque, no processo de gestão da UC, principalmente no que diz respeito ao planejamento do turismo na região da Trindade. Esse argumento parece estar em sintonia com aquele discutido por Irving (2008), para a qual a participação social e a gestão colaborativa do turismo entre os atores locais e os órgãos públicos (no caso, os trindadeiros e a administração do PNSB), representam um primeiro passo em direção a uma forma mais sustentável de desenvolvimento do turismo.

Assim, pela narrativa dos próprios trindadeiros, o turismo representa, simultaneamente, problema e oportunidade. Um problema a ser equacionado no que diz respeito à manutenção do modo de vida local e à conservação da natureza; e uma oportunidade com relação à geração de emprego e renda. Nesse contexto, os próprios moradores de Trindade percebem que uma parceria efetiva entre eles e a administração do PNSB representa um caminho possível para o gerenciamento dessas questões e, progressivamente, a implementação de uma via mais sustentável para o desenvolvimento do turismo na região.

\section{Turismo ou ecoturismo na vila de Trindade?}

Diante dos resultados discutidos pela pesquisa, centrada na percepção dos próprios atores locais, parece evidente que a relação entre 0 desenvolvimento turístico, a manutenção dos modos de vida local e as demandas de proteção da natureza no PNSB representa ainda uma equação sem resposta.

No que diz respeito às consequências do turismo para os modos de vida local, a problemática do aumento da renda versus a manutenção da cultura caiçara é fortemente controversa e entendida como uma questão ainda mal resolvida e fonte potencial de conflitos. Os trindadeiros não parecem ainda ter clareza sobre como equacionar e harmonizar as necessidades dos turistas, a diminuição dos efeitos da sazonalidade e o aumento de sua renda ao longo de todo o ano, com o compromisso de conservação da natureza e a valorização das práticas tradicionais. A população de Trindade enfatiza também a necessidade de valorização de 
sua própria cultura no processo de desenvolvimento do turismo na vila. $E$, assim, reforça, em seu discurso, a importância de dois pressupostos do ecoturismo: o compromisso de conservação ambiental e de valorização da cultura local.

Mas com relação à influência do turismo como alternativa para o fortalecimento do processo de proteção da natureza, uma questão central, reforçada pelos resultados da pesquisa, diz respeito à necessidade de controle do número de turistas na vila de Trindade. Sob a ótica dos moradores da Trindade, essa tendência vem assegurando um ganho com relação aos benefícios econômicos, a partir da ampliação do número de pousadas, campings e restaurantes. Porém, essa mesma tendência se expressa, simultaneamente, como uma ameaça à conservação da biodiversidade na região, em função do aumento da pressão antrópica sobre os recursos naturais e da falta de um melhor ordenamento do turismo na área.

Não se pode negligenciar, nesse contexto, que como a administração do PNSB esteve ausente durante muitos anos do local e, apenas recentemente, vem se manifestando com o compromisso efetivo de consolidação da área protegida (por meio de diretrizes de ordenamento e/ou restrições ao uso dos recursos naturais), parece haver uma grande desconfiança da população local com relação aos riscos futuros para o seu cotidiano. Tal desconfiança vem dificultando a consolidação de uma parceria mais concreta entre moradores e a administração do PNSB para o desenvolvimento do turismo nos moldes desejados ou segundo os pressupostos de ecoturismo na área. Essa dificuldade na consolidação de parcerias está evidentemente expressa nos casos discutidos sobre a proposta do estudo de capacidade de suporte, da cobrança de ingresso em áreas estratégicas de acesso ao interior do parque, da regularização dos quiosques da praia do Meio e da realização das operações de fiscalização nos principais feriados - "Operação Verão".

Sendo assim, uma estratégia para a explicitação dos diversos interesses e conflitos envolvidos na gestão do turismo e a construção de pactos com o objetivo de equacionar alguns dos mais graves problemas identificados constituem alternativas significativas para que a gestão pública possa assegurar uma relação de confiança com a população local e também para que possa conhecer os seus anseios e expectativas em relação à AP. Esta dinâmica tende a viabilizar um processo mais realista para a consolidação do Parque e para o desenvolvimento efetivo do ecoturismo, em longo prazo, segundo as premissas teóricas aqui adotadas para orientar o debate.

Levando-se em consideração que o ecoturismo tem, dentre seus pressupostos, o compromisso de valorização do patrimônio natural e cultural, o incentivo à conservação da natureza, a formação de uma consciência ambientalista através da interpretação crítica e engajada do ambiente e a promoção do bem-estar das populações envolvidas, é possível perceber, a partir dos problemas evidenciados na pesquisa, que 0 ecoturismo no Parque Nacional da Serra da Bocaina pode representar uma alternativa possível para a proteção da biodiversidade e para a conservação das tradições em Trindade, se os benefícios socioeconômicos por ele 
gerados estiverem associados aos compromissos de conservação do patrimônio cultural e natural (como discutido no referencial teórico deste artigo), e se os administradores do PNSB partirem da premissa que a população local deve estar inserida como protagonista no processo de planejamento e gestão do parque.

Assim, por todas estas razões, o ecoturismo no caso particular da vila de Trindade, representa, ainda, uma potencialidade a ser consolidada nos próximos anos. E para que se torne realidade, é fundamental que este não seja apenas entendido na lógica romântica de viagens à natureza, mas como fenômeno contemporâneo complexo, com inúmeras implicações nos planos ambiental, social, econômico, político e, principalmente, ético ${ }^{5}$.

\section{Referências Bibliográficas}

BALDIN, N.; MUNHOZ, E. M. B. Snowball (Bola De Neve): Uma Técnica Metodológica para Pesquisa em Educação Ambiental Comunitária. Anais do $\mathbf{X}$ Congresso Nacional de Educação. PUC, Curitiba, 2011.

BODSTEIN, L.C.A. Conservação ambiental e desenvolvimento turístico no Brasil: conciliação e perspectiva. Turismo em Análise. 1992, p.99-112.

BRASIL. Lei $n^{\circ}$ 9.985, de 18 de julho de 2000. Sistema Nacional de Unidades de Conservação.

CONTI, B.R.; FONTANA, A.; LIVINO, F.F.; IRVING, M.A. O Parque Nacional da Serra da Bocaina: Entre a montanha e o mar. In: IRVING, M.A.; CORRÊA, F.V.; ZARATTINI, A.. (Orgs.). Parques Nacionais no Rio de Janeiro: contexto e desafios. Folio Digital: Letra e Imagem, Rio de Janeiro. 2013.

CONTI, B.R. Proteção da Natureza e Qualidade de Vida em Trindade (Paraty - RJ): para entender o ecoturismo no Parque Nacional da Serra da Bocaina. 2011. 207p. Dissertação (Mestrado em Psicossociologia de Comunidades e Ecologia Social) - Instituto de Psicologia, Universidade Federal do Rio de Janeiro (UFRJ), Rio de Janeiro - RJ, 2011.

CONTI, B.R.; IRVING, M.A.; CORRÊA, F.V. Parque Nacional da Serra da Bocaina/RJ: Qual a relação com a Vila de Trindade?. In: V Seminário Brasileiro de Áreas Protegidas e Inclusão Social. Manaus, 2011.

CONTI, B.R.; IRVING, M.A. Refletindo sobre a relação entre proteção da natureza e o ecoturismo em Parques. V Encontro Nacional da ANPPAS. Florianópolis, 2010.

CORIOLANO, L.N.M. A exclusão e a inclusão social e o turismo. Revista de Turismo y Patrimônio Cultural. v. 3, n. 2, 2005.

COSTA, P.C. Ecoturismo. São Paulo: Ed. Aleph, 2002.

DEORI, S.; DAS, N. Ecotourism in wetland environment. Revista Brasileira de Ecoturismo. São Paulo, v.6, n.2, 2013, p.354-365.

Eagles, P.F.J. Understanding the Market for Sustainable Tourism. In: Stephen F. McCool and Alan E. Watson. Linking tourism, the environment and sustainability. Minneapolis, 1995.

EMBRATUR. Manual de Municipalização do Turismo. Embratur, Brasília, 1994. 
FONTANA, A.; FREY, J.H. Interviewing: the art of science. In: DENZÏN, N.K.; LINCOLN, Y.S. Handbook of qualitative research. Thousand Oaks: Sage, 1994.

GODOI, C.K.; BALSINI, C.P.V. A pesquisa qualitativa nos estudos organizacionais brasileiros: uma análise bibliométrica. In: SILVA, A.B.; GODOI, C.K.; BANDEIRA-DEMELO, R. (Orgs). Pesquisa qualitativa em estudos organizacionais: paradigmas, estratégias e métodos. 2. ed. São Paulo, 2010, p. 89-113.

GOODEY, J.; GOLD, B. - Geografia do comportamento e da percepção. Belo Horizonte: Ed. da UFMG, 1986.

GRANT, J. The National Ecotourism Programme: Australia, Report. Tourism Recreation. 1995.

IBAMA. MINISTÉRIO DO MEIO AMBIENTE/IBAMA/DIREC. Plano de Manejo do Parque Nacional da Serra da Bocaina: encarte n.5. FEC/UNICAMP, Brasília, 2002.

IRVING, M.A; MATOS, K. Gestão de Parques Nacionais no Brasil: projetando desafios para a implementação do Plano Nacional Estratégico de Áreas Protegidas. Revista Floresta e Ambiente. Rio de Janeiro, v.13, n.2, 2006, p.89- 96.

IRVING, M.A. Ecoturismo Em Áreas Protegidas: Da Natureza Ao Fenômeno Social. In: CASTILHO, N.; NEIMAN, N.; CASTILHO, V. Pelas trilhas do Ecoturismo. RIMA, São Carlos, 2008, p.3-15.

LUCHIARI, M.T.D.P. Lugar no mundo Contemporâneo: Turismo e Urbanização em Ubatuba-SP". Tese de Doutorado. IFCH-UNICAMP, Campinas, 2000.

MARTINS, S.R. O. Desenvolvimento Local: questões conceituais e metodológicas. Revista Interações - Revista Internacional de Desenvolvimento Local, v. 3, n. 5, p.51-59, 2002.

MENDONÇA, T.C.M. Turismo e participação comunitária: Prainha do Canto Verde a "Canoa" que não quebrou e a "Fonte" que não Secou?". Dissertação (Mestrado em Psicossociologia de Comunidade e Ecologia Social) UFRJ, Programa EICOS/IP, 2004.

MULS, L.M. Desenvolvimento Local, Espaço e Território: O Conceito de Capital Social e a Importância da Formação de Redes entre Organismos e Instituições Locais. Revista EconomiA. Brasília, v. 9, n. 1, p.1-21, 2008.

MURTA, S.M.; GOODEY, B. Interpretação do patrimônio para visitantes: um quadro conceitual. In. MURTA, S.M.; ALBANO, C. (org.). Interpretar o patrimônio: um exercício do olhar. EdUFMG e Território Brasilis: Belo Horizonte, 2002, p.13-46.

NELSON, S.P.; PEREIRA, E.M. Ecoturismo: práticas para turismo sustentável. Manaus: Valer, 2004.

NEIMAN, Z.; MENDONÇA, V.M. e SCHLINDWEIN, M.N. Eu e a Brisa: reflexões sobre a percepção ambiental no turismo. Revista Brasileira de Ecoturismo. São Paulo, v. 1, n. 1, 2008.

OLIVEIRA, A.C. Turismo em áreas 'menos desenvolvidas': caracterização, desenvolvimento e planejamento turístico da Vila de Trindade, município de 
Paraty/Rio de Janeiro - Brasil. Revista de Turismo y Patrimônio Cultural. Tenerife, vol.3, n.1, 2005, p.149-169.

PEREIRA, F.M. Vila da Trindade, Paraty, RJ: Turismo Sustentável?. Uni ABC, Santo André, 2001.

RODRIGUES, C.G.O. 0 uso público nos Parques Nacionais: a relação entre as esferas pública e privada na apropriação da biodiversidade. Tese de Doutorado, UNB, Brasília, 2009.

SAMPAIO, C.A.C.; ZECHNER, T.C.; HENRÍQUEZ, C. Pensando o conceito de turismo comunitário a partir de experiências brasileiras, chilenas e costarriquenha. In: Anais do II Seminário Internacional de Turismo Sustentável (SITS), Fortaleza (CE), 2008.

SANSOLO, D.G. Centralismo e Participação na Proteção da Natureza e Desenvolvimento do Turismo no Brasil. In: IRVING. M.A. (Org.). Áreas Protegidas e Inclusão Social: construindo novos significados. Aquarius, Rio de Janeiro, 2006, p. 131-155.

SANSBELLÓ, M.R.F.; FLORES, J.C.M. Ecoturismo itinerante en el Trapecio, Amazónico Colombiano. Estudios y Perspectivas en Turismo. Espanha, vol.12, 2003, p.48-62.

SILVEIRA, M.A.T. Turismo, Políticas de Ordenamento Territorial e Desenvolvimento. Um foco no Estado do Paraná no Contexto Regional. São Paulo: FFLCH/USP. Tese de Doutorado, 2002.

TURNER, L.; ASH, J. La horda dorada. Endymion, Madrid, Espanha, 1991. WEIGHT, P. Ecoturism: ethics or eco-sell. Journal of Travel Research. 1993. Disponível em: http://jtr.sagepub.com/content/31/3/3.abstract. Acessado em 24/10/2013.

WESTERN, David. Definindo ecoturismo. In: LINDBERG, K.; HAWKINS, E. D. (editores) Ecoturismo: um guia para planejamento e gestão. São Paulo: Senac, 1999. 2. ed. P. $13-22$.

\section{Notas}

${ }^{1}$ Desenvolvimento local pode ser entendido como uma alternativa à falência dos modelos tradicionais de desenvolvimento fundados seja na compreensão do Estado nacional como principal agente propulsor do desenvolvimento, seja nas funções alocativas do mercado como facilitador do ótimo econômico. A mobilização dos atores locais, a formação de redes entre organismos e instituições locais e uma maior cooperação entre as instituições situadas em um mesmo território, são alternativas que têm possibilitado novas formas de inserção produtiva e uma atenuação das desigualdades sociais. Essas formas não substituem a ação do mercado ou a ação estatal, mas sobrepõem-se a estas na medida em que os atores locais elaboram, a partir de suas instituições próprias e de seus organismos específicos, uma estratégia de desenvolvimento local (MULS, 2008). Neste processo, a participação comunitária seria uma condição do desenvolvimento local, seja em sua efetivação, seja em termos de continuidade da proposta, devendo ser este entendido como a satisfação das necessidades humanas fundamentais através do protagonismo real e verdadeiro de cada ator local. Criar as condições para que a sociedade efetivamente exerça este protagonismo se afigura como o maior desafio para que o desenvolvimento local aconteça, considerando estar o Brasil diante de realidades locais nas quais persistem algumas lacunas centrais para o exercício da cidadania, a identificação sociocultural e territorial e o fortalecimento do sentido de vizinhança (MARTINS, 2002). Para Rozas (1998), desenvolvimento local é a organização comunitária em torno de um planejamento para o desenvolvimento, segundo uma perspectiva de construção social, constituindo assim estratégia fundamental para a superação da pobreza. Não se trataria, contudo, de buscar 
tão somente $\mathrm{o}$ atendimento às carências materiais, mas também a identificação e a promoção das qualidades, capacidades e competências existentes na comunidade e no lugar (Esta discussão poder ser aprofundada em Muls, 2008 e Martins, 2002).

${ }^{2}$ A Convenção sobre a Diversidade Biológica (CDB) constitui um tratado da Organização das Nações Unidas e um dos mais importantes instrumentos internacionais relacionados à temática ambiental. A Convenção está estruturada sobre três bases principais - a conservação da diversidade biológica, o uso sustentável da biodiversidade e a repartição justa e equitativa dos benefícios provenientes da utilização dos recursos genéticos - e se refere à biodiversidade em três níveis: ecossistemas, espécies e recursos genéticos. A Convenção abarca tudo o que se refere direta ou indiretamente à biodiversidade - e ela funciona, assim, como uma espécie de arcabouço legal e político para diversas outras convenções e acordos ambientais mais específicos. Disponível em: http://www.mma.gov.br/biodiversidade/convencao-da-diversidade-biologica. Acessado em 10 de abril de 2014.

${ }^{3}$ Disponível em: http://www.bonitobrazil.com.br/NOTICIA-3371ECOTURISMO+TEM+CRESCIMENTO+MAIOR+QUE+O+TURISMO+SEGUNDO+OMT.ht

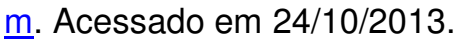

${ }^{4}$ Disponível em:

http://www.dadosefatos.turismo.gov.br/dadosefatos/geral interna/noticias/detalhe/20111011 -2.html. Acessado em 24/10/2013.

${ }^{5}$ Esta pesquisa é inspirada na dissertação de mestrado "Proteção da Natureza e Qualidade de Vida em Trindade (Paraty - RJ): Para Entender o Ecoturismo no Parque Nacional da Serra da Bocaina", defendida em janeiro de 2011 no programa de pós-graduação em Psicossociologia de Comunidades e Ecologia Social/IP/UFRJ.

Bruna Ranção Conti: Universidade Federal do Rio de Janeiro, Rio de Janeiro, RJ, Brasil.

E-mail: bruna-conti@hotmail.com

Link para o currículo Lattes: http://lattes.cnpq.br/5130616222632742

Marta de Azevedo Irving: Universidade do Grande Rio, Rio de Janeiro, RJ, Brasil.

E-mail: mirving@mandic.com.br

Link para o currículo Lattes: http://lattes.cnpq.br/1912229324377473

Data de submissão: 28 de janeiro de 2014

Data de recebimento de correções: 05 de junho de 2014

Data do aceite: 06 de junho de 2014

Avaliado anonimamente 